\title{
Las indicaciones de origen protegidas como elemento de diferenciación de los productos agroalimentarios: el caso del jamón en España
}

\section{Protected indications of origin as differentiation cue of food products: the Spanish ham case}

\author{
Juan Carlos Gázquez Abad \\ Francisco J. Martínez LóPEZ ${ }^{2}$ \\ VAnesa Barrales Molina ${ }^{3}$ \\ Universidad de Almería (España) \\ Universidad de Granada (España)
}

Recibido ell1 de octubre de 2010, aceptado el 16 de mayo de 2011

$\mathrm{N}^{\mathrm{o}}$ de clasificación JEL: M31, Q13

DOI: $10.5295 / \mathrm{cdg} .100264$ jg

\section{Resumen:}

El origen es una de las estrategias utilizadas tradicionalmente por parte de los productos agroalimentarios para diferenciar una oferta de otra en el mercado. ¿Es útil el origen en la estrategia competitiva de este tipo de productos?, ¿realmente permite diferenciar las ofertas? Este trabajo pretende realizar una reflexión acerca del papel que el origen puede jugar como elemento de diferenciación de los productos agroalimentarios. Para ilustrar los argumentos teóricos desarrollados, se realiza un análisis en profundidad del sector del jamón con Indicación de origen en España. En este sector existen únicamente seis denominaciones geográficas, lo que nos va a permitir un mejor análisis de los aspectos relacionados con el origen del producto.

Palabras clave:

Diferenciación; Denominación de Origen Protegida; Indicación Geográfica Protegida; Jamón.v

Abstract:

The 'country/region of origin' is a traditionally used strategy by food companies in order to diferentiate their production from each other. Is the origin an useful strategy? Does it lead to differentiate a company's offer? This paper aims to resolve these questions from a theoretical perspective. In addition, a descriptive analysis of Spanish Designation of Origin's ham sector is developed. Such sector comprises only six Designations, so an in-deep analysis of all aspects related to place of origin will be easier

\footnotetext{
${ }^{1}$ Universidad de Almería. Departamento de Dirección y Gestión de Empresas. Facultad de CC.EE. y Empresariales. Ctra.Sacramento s/n.La Cañada de San Urbano. 04120.Almería. jcgazque@ual.es

${ }^{2}$ Universidad de Granada. Departamento de Comercialización e Investigación de Mercados. Facultad de CC.EE. y Empresariales. Campus Universitario de Cartuja, 18071. Granada. fjmlopez@ugr.es

${ }^{3}$ Universidad de Granada. Departamento de Organización de Empresas. Facultad de CC.EE. y Empresariales. Campus Universitario de Cartuja, 18071. Granada. vanesabm@ugr.es
} 
Las indicaciones de origen protegidas como elemento de diferenciación de los productos agroalimentarios...

\section{Keywords:}

Diferentiation; Protected Designations of Origin, Protected Geographical Indications, Ham. 


\section{INTRODUCCIÓN}

Durante el proceso de compra, el consumidor tiene a su disposición una elevada cantidad de información relacionada con las diferentes alternativas de elección (Blackwell et al., 2006). El volumen de información disponible es especialmente importante en categorías como los productos agroalimentarios en los que el nivel de variedad es muy importante (Ozretic-Dosen et al., 2007). En este contexto, las indicaciones de origen protegidas -como elemento diferenciador de la calidad de los productos- se configuran como una estrategia muy adecuada para destacar las cualidades de alimentos y bebidas ante la demanda de los consumidores. Este esfuerzo empresarial e institucional con objeto de difundir la calidad de los productos es consecuencia de la creciente exigencia del consumidor con relación a todos los aspectos relacionados con la composición y la calidad de los alimentos que consume (Martín, 2009).

Las denominaciones de origen nacen de la voluntad de algunos países de proteger sus productos agrícolas y alimenticios por su origen geográfico. Las distinciones de calidad ligadas al origen geográfico o a los procedimientos ecológicos en el proceso de producción de los distintos alimentos y bebidas, han sido algunas de las estrategias de diferenciación más desarrolladas durante las últimas décadas en el sector agroalimentario europeo (Martín, 2006). La diferenciación del producto aparece como una estrategia que intenta captar el gasto de los consumidores dentro de una categoría de producto (la alimentación fresca) en la que existen muchas dificultades para discriminar los productos y no todos cuentan con marcas -como en el caso de la alimentación envasada- que sirvan para establecer una diferenciación importante (Martín, 2009). La diferenciación basada en aspectos relacionados con el origen debe servir para ensalzar aquellos productos que optan más por la especificidad que por la estandarización. No obstante, la diferenciación de los productos agroalimentarios resulta compleja en el mercado español, dado el elevado número de distinciones que existen tanto a nivel nacional como autonómico, lo que reduce, en muchos casos, el poder de la distinción.

En este trabajo se pretende ofrecer una visión general del panorama de las Indicaciones de Origen Protegidas ${ }^{1}$ (I.O.P.) de productos agroalimentarios, analizando el significado y la utilidad de las mismas, y las implicaciones que se derivan de ellas para las empresas desde un punto de vista comercial. Para ilustrar este análisis vamos a centrarnos en el sector del jamón en nuestro país. En este sentido, se desarrolla un análisis descriptivo de cada una de las (seis) distinciones que existen en España, mostrando cuál es la situación actual del sector, sus oportunidades y amenazas y la evolución de las cifras de negocio en los últimos años. Adicionalmente, y con objeto de completar este análisis descriptivo, se utilizan series temporales para realizar una previsión de las ventas del sector en los próximos cinco años. La elección del sector del jamón se justifica por la importancia y tradición que este producto tiene en nuestro país, así como por el reducido número de distinciones que existen en dicho sector.

\footnotetext{
${ }^{1}$ En este trabajo, utilizaremos este término para referirnos indistintamente a las Denominaciones de Origen Protegidas (D.O.P.) o a las Indicaciones Geográficas Protegidas (I.G.P.)
} 


\section{LAS INDICACIONES DE ORIGEN PROTEGIDAS: LAS DENOMINACIONES DE ORIGEN PROTEGIDAS Y LAS INDICACIONES GEOGRÁFICAS PROTEGIDAS}

\subsection{Origen de las Indicaciones de Origen Protegidas}

La utilización del origen como elemento diferenciador de los productos agroalimentarios no es algo nuevo. La primera denominación de origen realmente protegida se ubica en la Francia del siglo XVII, con la declaración del Parlamento de Toulouse acerca de la exclusividad que tenía el queso que se curaba en la región de Roquefort.

El componente típico se constituye como un elemento que confiere a los productos una calidad determinada. De esta manera, se vincula un producto con un lugar geográfico determinado, surgiendo, en ese momento, el concepto de indicación geográfica. La vinculación de determinados productos surge desde el principio como realidades históricas, culturales, económicas y sociales que, aunque no hayan sido reconocidos desde el punto de vista legal hasta bien entrado el siglo XX, tienen una larga tradición en muchos países, muy especialmente en el mediterráneo europeo (Cambra y Villafuerte, 2009). La vinculación geográfica se ha utilizado, en muchos casos también, como barrera a la importación de productos foráneos (Chambolle y Giraud-Héraud, 2005).

En España, ya en 1902 se reconocía en la Ley de 16 de mayo sobre Propiedad Industrial y Comercial la utilización de "marcas colectivas" con el nombre geográfico "del lugar de fabricación, elaboración o extracción de un producto". Sin embargo, no es realmente hasta 1932 cuando se produce la introducción de la denominación de origen en nuestro ordenamiento jurídico (Barco, 2007). El año 1970 es clave en la evolución de este concepto; así, en la Ley 25/1970 de 2 de diciembre, de Estatuto de la Viña, del Vino y los Alcoholes, se dedica un apartado completo a la "protección de la calidad", perfeccionando el régimen de las denominaciones de origen y recogiendo los avances que se habían producido en esa fecha a partir de los acuerdos a nivel internacional, como en el "arreglo de Lisboa" de 1958, en el que se produce el reconocimiento de las denominaciones de origen a nivel internacional. En este sentido, en este documento se proporciona la primera definición de "denominación de origen" como (Barco, 2007:28): "la denominación geográfica de un país, de una región o de una localidad que sirva para designar un producto del mismo y cuya calidad o características se deban exclusiva o esencialmente al medio geográfico, comprendiendo los factores naturales y los factores humanos".

Fue en el sector vitivinícola donde las denominaciones de origen fueron primero objeto de un régimen de protección. Sin embargo, además de los productos agrícolas, las I.O.P. pueden ser útiles también para destacar cualidades específicas en otras categorías, de modo que el lugar de origen puede ser un pueblo, una ciudad, región o país (Cambra y Villafuerte, 2009) (e.g., el término Switzerland o Swiss, considerado en muchos países como una I.O.P. para los productos fabricados en aquél país, en particular para los relojes).

\subsection{Concepto de Indicación de Origen Protegida}

El contexto agroalimentario de la UE es en el que mayor desarrollo ha alcanzado el desarrollo de indicaciones de origen protegidas (Schulze et al., 2008). Esto se debe al ca- 
rácter simbólico que la alimentación tiene en la tradición socio-cultural de la mayor parte de culturas europeas (Krystallis y Ness, 2005). Sin embargo, no fue hasta el año 1992 cuando se produjo el reconocimiento a nivel legislativo de las denominaciones de calidad en productos agroalimentarios en general (antes solo se aplicaban al vino). El desarrollo normativo de las I.O.P. culminó en 2006 con el Reglamento (CE) 510/2006 del Consejo, de 20 de marzo sobre la protección de las indicaciones geográficas y de las denominaciones de origen de los productos agrícolas y alimenticios. El artículo 2 de dicho Reglamento distingue los siguientes términos:

a) 'Denominación de origen': el nombre de una región, de un lugar determinado o, en casos excepcionales, de un país que sirve para designar un producto agrícola o un producto alimenticio: (i) originario de dicha región, de dicho lugar determinado o de dicho país; (ii) cuya calidad o características se deban fundamental o exclusivamente al medio geográfico con sus factores naturales y humanos, y (iii) cuya producción, transformación y elaboración se realicen en la zona geográfica delimitada.

b) "Indicación Geográfica": el nombre de una región, de un lugar determinado o, en casos excepcionales, de un país, que sirve para designar un producto agrícola o un producto alimenticio: (i) originario de dicha región, de dicho lugar determinado o de dicho país; (ii) que posea una cualidad determinada, una reputación u otra característica que pueda atribuirse a dicho origen geográfico, y (iii) cuya producción, transformación o elaboración se realicen en la zona geográfica delimitada.

Además de estas dos figuras, hay que hacer referencia al concepto "Especialidad tradicional garantizada (E.T.G.)", que si bien no hace referencia al origen, tiene por objeto destacar una composición tradicional del producto o un modo de producción tradicional (Martín, 2006). En nuestro país, ejemplos de productos acogidos a esta denominación son el jamón serrano, la leche certificada de granja, los panellets y las tortas de aceite (Cambra y Villafuerte, 2009).

Por tanto, la condición necesaria para que una Denominación pueda ostentar la indicación D.O.P. es que todas las fases de producción se realicen en la zona geográfica delimitada, de modo que las características del producto dependan exclusiva o esencialmente de su origen geográfico. Por el contrario, la denominación de I.G.P. requiere que, al menos, una de las fases de la producción se realice en la zona geográfica en particular, de modo que el vínculo con la misma debe justificarse por estar relacionadas con esa zona geográfica alguna cualidad específica del producto. Sin embargo, y a pesar de esta distinción, tradicionalmente las D.O.P. y las I.G.P. han sido consideradas y analizadas de forma conjunta bajo el término I.G. (Indicación geográfica) o D.G. (Denominación geográfica), agrupando bajo este concepto un producto cuyo aspecto más característico y diferencial es que sus cualidades y su reputación son atribuibles a un lugar (Cambra y Villafuerte, 2009). Por esta razón, podemos afirmar que desde el punto de vista del consumidor y el mercado no se percibe diferencia alguna entre ambos conceptos (Barco, 2007; MAPA, 2005; Martín, 2009). De hecho, la diferenciación de los productos agroalimentarios resulta compleja en el mercado español puesto que se han configurado muchas distinciones tanto a nivel nacional como en el entorno de las CC.AA. (Martín, 2009). En este sentido, en diferentes estudios realizados recientemente por el Ministerio de Agricultura español se desprende que, en general, el consumidor muestra cierto desconocimiento sobre lo que son las D.O.P., y un gran desconocimiento sobre las I.G.P. y las E.T.G. (MAPA, 2006). 


\subsection{La Indicación de Origen Protegida como herramienta de marketing}

En el marco competitivo actual en el que la estandarización se está convirtiendo en una opción estratégica para muchas empresas, la diferenciación se configura como una de las vías que una empresa tiene para poder competir en mejores condiciones e incrementar su cuota de cliente. En particular, en el contexto del sector agroalimentario, la mayor demanda de productos de calidad ha supuesto una oportunidad de mercado, atractiva y fácilmente aprovechable en el desarrollo de las estrategias comerciales de las empresas que operan en dicho sector (Caldentey y Gómez, 1996, 1997; Gómez y Caldentey, 1999; Yagüe, 1996). Establecer la diferenciación sobre la base de una calidad determinada por el origen del producto, permite a las empresas el aprovechamiento de puntos fuertes derivados de la tradición, la experiencia y el know-how en la elaboración del producto que existe en una zona geográfica, así como en las empresas en ella instaladas. Con esto se obtienen importantes beneficios a través de la posición privilegiada que el producto ocupa en el mercado. De hecho, en el contexto agroalimentario la importancia de las I.O.P. en el desarrollo de estrategias de diferenciación es un hecho constatado (Jiménez, 2002). Entre los productos agroalimentarios, el vino es probablemente el mejor ejemplo del uso del origen como elemento de prestigio de las características cualitativas de un producto (Bertozzi y Panari, 1993).

La I.O.P. facilita la integración, en un solo concepto, de diferentes aspectos relativos al producto, su calidad y la tradición y el saber-hacer de las empresas y de la zona de procedencia. La construcción de un fuerte capital comercial de la I.O.P., fundamentado en el conocimiento y preferencia de los consumidores, viene a constituir hoy en día una de las principales "armas" con las que cuentan las empresas agroalimentarias para competir en los mercados. De hecho, existen autores (e.g., Gürhan-Canli y Maheswaran, 2000; Maheswaran y Chen, 2006) que indican que la preferencia por los productos con origen se desarrolla a partir de componentes racionales (e.g., la calidad y la reputación), pero también a partir de componentes emocionales. Podríamos decir que se establece un "vínculo" entre consumidor, producto y origen (Maheswaran y Chen, 2006). Es por ello que el capital de marca creado por la I.O.P. es fundamental, mucho más si tenemos en cuenta el desconocimiento que el consumidor suele tener de los aspectos relacionados con la producción (Eden et al., 2008).

El nombre geográfico protegido mediante una I.O.P. se configura como una marca colectiva o pública, con acceso restringido no sólo por el origen, sino también por las condiciones que se imponen a la naturaleza y a la calidad de los productos que se encuentran bajo su amparo (Jiménez y Gómez, 1997). A modo de marca paraguas, la I.O.P. es usada para comercializar diferentes productos en diversos mercados, dejando total libertad a cada una de las marcas que bajo su manto se amparan para que desarrollen su propia comunicación, pero suministrando globalmente respaldo y valor. Por tanto, la marca que representa la I.O.P. no hace referencia, únicamente, a un origen geográfico específico, sino que abarca también todo el "saber hacer" y la tradición de las empresas del lugar en la elaboración de un producto que cuenta con unos rasgos diferenciales. No obstante, y tal y como indican Cambra y Villafuerte (2005), en muchos casos el margen de maniobra de las I.O.P. con respecto al proceso productivo es mucho más reducido que el que puede tener una marca que se encuentre fuera de dicha Denominación, en términos de las materias primas utilizadas o las características del proceso de elaboración. De hecho, y dado que las alternativas de aprovisionamiento están limitadas a la oferta de la zona geográfica, el precio que éstas pue- 
de alcanzar puede ser muy elevado. En opinión de estos autores, la limitación en el margen de maniobra se extiende, incluso, al propio proceso y a las estrategias de comercialización utilizadas. Por todos estos motivos, los agentes que participan en aquellas categorías amparadas por una I.O.P. suelen ser más propensos a colaborar y a compartir información, en la medida en la que el éxito de unos va a depender, claramente, de los otros (Polo y Cambra, 2006). De hecho, la cooperación entre los agentes económicos de la misma zona es una de las tres funciones señaladas por Sanz y Macías (2005) dentro de los principales objetivos económicos que tiene una I.O.P.

Adicionalmente, y de forma frecuente, el cumplimiento de los protocolos de calidad exigidos por los Consejos Reguladores provocan la aparición de costes adicionales en todo el proceso de elaboración, lo que va a impedir el establecimiento de precios reducidos que faciliten la competencia de los productos amparados por la I.O.P. En este sentido, en la medida en la que el mercado sea capaz de valorar la diferenciación vinculada al origen y esté dispuesto a pagar un precio mayor por el producto que procede de dicho lugar, esto no será un problema (Cambra y Villafuerte, 2009). No obstante, no existen garantías reales de que el mercado esté dispuesto a pagar dicho "sobreprecio" por un producto procedente de un origen específico, aún cuando se reconoce en la literatura la imagen de calidad de los productos con origen (Bertozzi y Panari, 1993), así como la credibilidad que el consumidor suele expresar hacia los mismos (Moussa y Touzani, 2008). De hecho, algunos trabajos centrados en marcas de productos orgánicos con origen (e.g., Hustvedt y Bernard, 2008) indican que los consumidores están dispuestos a pagar ese sobreprecio siempre que perciban claramente el valor añadido (en este caso, beneficio para la salud) que dichos productos aportan. Consecuencia de todo esto, en la medida en la que la notoriedad y el poder de una marca sea mayor, las empresas individuales van a preferir desarrollar su actividad comercializadora de forma independiente en lugar de "atarse" a una I.O.P. (Ahmed et al., 2004). No obstante, en condiciones en las que la dimensión del productor no sea muy elevada, no posea recursos económicos y humanos suficientes y, en definitiva, ante una falta de penetración en los mercados y de notoriedad suficientes, los incentivos para producir al amparo de una I.O.P. van a aumentar, al igual que el interés por desarrollar acciones comerciales conjuntas, respaldando, de este modo, la marca individual con la marca paraguas-colectiva que supone la I.O.P. (Cambra y Villafuerte, 2009).

Desde la perspectiva del mercado, la literatura de marketing ha contrastado de modo amplio la importancia que el origen tiene en las evaluaciones que el consumidor hace de los productos (Häubl y Elrod, 1999; Verlegh et al., 2005), así como en su intención de compra (véanse e.g., Al-Sulaiti y Baker, 1998; Insch y McBride, 2004; Javalgi et al., 2001; Ozsomer y Cavusgil, 1991; Pharr, 2005; Srinivasan y Jain, 2003; Verlegh y Steenkamp, 1999). Así, la presencia de la I.O.P. busca facilitar al consumidor el reconocimiento del producto y la percepción de una calidad, al igual que un grado de diferenciación superior. En este sentido, las cualidades específicas que el producto consigue gracias al medio natural y humano van a permitir crear una imagen única, capaz de crear valor añadido y de incrementar la preferencia en la mente del consumidor (Van Ittersum et al., 2003). Adicionalmente, la existencia de un indicador de procedencia o calidad va a hacer que el consumidor perciba o refuerce una serie de asociaciones positivas con el producto, que, en muchos casos, puede llegar a incrementar su intención de compra (Balabanis y Diamantopoulos, 2008). Sin embargo, es necesario que el consumidor sea, efectivamente, capaz de distinguir claramente cuál es el origen 
de un producto (Liefeld, 1993), dado que en la actualidad la proliferación de marcas globales y el uso por parte de muchas empresas de múltiples países para desarrollar el proceso de elaboración y desarrollo del producto puede dificultar dicha identificación (Han y Terpstra, 1988; Maronick, 1995; Chao, 1998). Incluso, muchos fabricantes y distribuidores utilizan nombres de marcas en lenguas que sugieren un origen diferente al que realmente tiene dicha marca (Samiee et al., 2005). No obstante, este problema se minimiza en el caso de las I.O.P., en las que la identificación del origen por parte del consumidor es inmediata, si bien es cierto que en muchos casos el consumidor puede tener cierto desconocimiento de la ubicación y las características del área geográfica del que procede el producto (Liefeld, 1993).

\section{LAS INDICACIONES DE ORIGEN PROTEGIDAS EN ESPAÑA: EL JAMÓN}

En España, existen múltiples diferenciaciones que reconocen la calidad de alimentos y bebidas dentro del mercado de productos agroalimentarios (Martín, 2009). Estas distinciones se realizan tanto a nivel nacional (en el marco de las directrices europeas), como a nivel autonómico. La tabla 1 muestra las 141 Indicaciones de Origen (D.O.P. e I.G.P.) registradas entre los principales productos agroalimentarios (excluyendo vinos y bebidas espirituosas).

Tabla 1

Productos agroalimentarios amparados en D.O.P.e I.G.P.

\begin{tabular}{lcccc}
\hline \multicolumn{1}{c}{ Producto } & $\begin{array}{c}\mathrm{N}^{\mathrm{o}} \text { de } \\
\text { Denominaciones }\end{array}$ & $\begin{array}{c}\mathrm{N}^{\mathrm{o}} \text { de industrias } \\
\text { inscritas }\end{array}$ & $\begin{array}{c}\text { Volumen } \\
\text { comercializado (Tm.) }\end{array}$ & $\begin{array}{c}\text { Valor económico } \\
\text { (Mill. euros) }\end{array}$ \\
\hline Aceite de oliva virgen & 24 & $421^{\mathrm{a}}$ & 24.166 & 87,53 \\
Arroz & 3 & 17 & 35.388 & 43,16 \\
Carnes frescas & 15 & $247^{\mathrm{b}}$ & 34.688 & 142.05 \\
Condimentos y especias & 3 & $28^{\mathrm{c}}$ & 1.562 & 6,90 \\
Embutidos & 3 & 55 & 2.876 & 13,32 \\
Frutas & 16 & 238 & 82.086 & 81,96 \\
Hortalizas & 19 & 106 & 19.476 & 86,64 \\
Jamones & 6 & 277 & $1.413 .522^{\mathrm{d}}$ & 129,45 \\
Legumbres & 7 & 67 & 499 & 2,20 \\
Mantequillas & 2 & 2 & 493 & 2,87 \\
Pescados y moluscos & 3 & 12 & 2.900 & 41,59 \\
Miel & 3 & 78 & 119 & 2,85 \\
Otros productos cárnicos & 2 & 41 & 776 & 13,59 \\
Panadería, pastelería y & 10 & 128 & 10.526 & 38,39 \\
repostería & 24 & 463 & 21.904 & 191,62 \\
Quesos & 1 & 19 & $4.879^{\mathrm{e}}$ & 0,99 \\
Sidra & & & & \\
\hline
\end{tabular}

Fuente: Martín (2009) ${ }^{\mathrm{a} E n v a s a d o r a s ~ y ~ a l m a z a r a s ~} \quad{ }^{\mathrm{b}}$ Mataderos y salas de despiece ${ }^{\mathrm{c}}$ Envasadoras ${ }^{\mathrm{d}}$ Número piezas ${ }^{e}$ Hectolitros 
Las 141 Indicaciones de Origen que existen en la actualidad suponen un importante incremento respecto al año 1987, año de ingreso de España en la CEE. De hecho, en aquel momento únicamente existían 12 denominaciones ( 7 en quesos, 2 en aceite de oliva, 2 en jamón y 1 en arroz). En el contexto actual, el mayor peso lo tienen el aceite de oliva y los quesos, aglutinando conjuntamente un tercio del total de I.O.P. Con relación al valor económico de los productos comercializados bajo I.O.P. destacan los quesos, las carnes frescas y los jamones (192, 142 y 129 millones de $€$ ). La figura 1 muestra la participación por productos y valor económico de cada una de las categorías de producto.

Figura 1

Productos agroalimentarios amparados en D.O.P. e I.G.P.

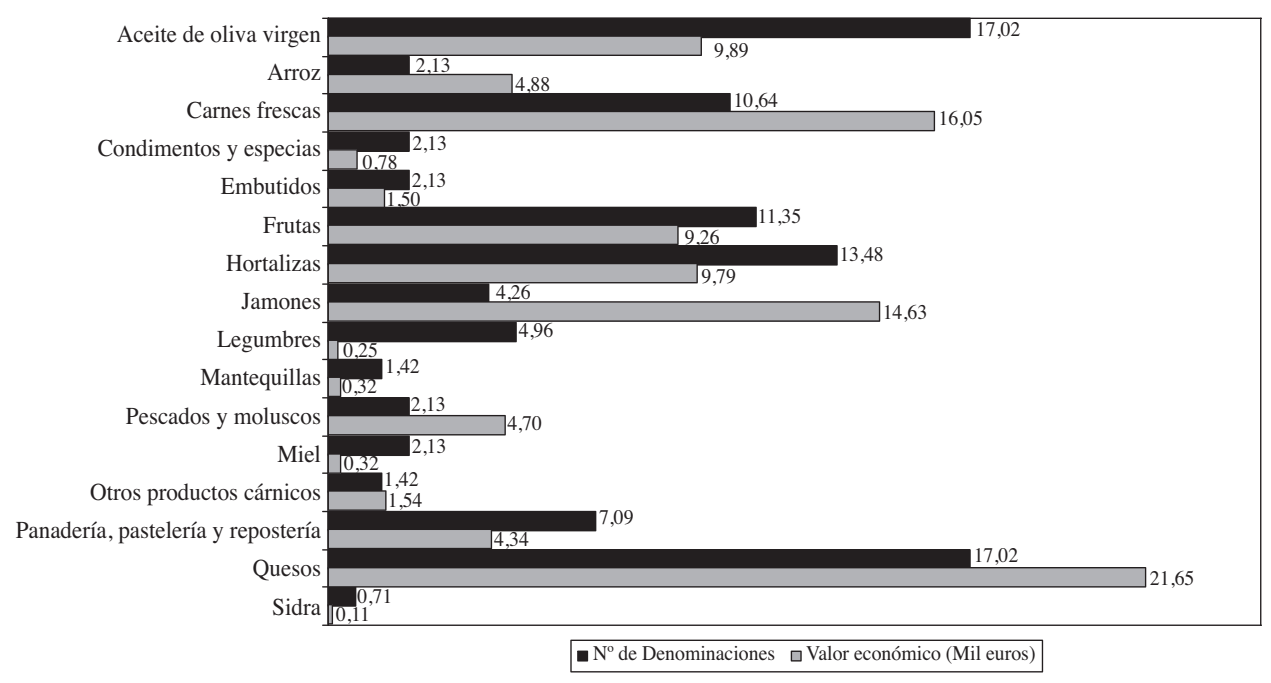

Fuente: Martín (2009)

Como podemos observar en la figura 1 , los quesos aglutinan el 17\% del número total de I.O.P. y casi el $22 \%$ de la facturación de las mismas. Los productos cárnicos tienen una importancia similar, al significar el 14\% del total de las denominaciones geográficas y el $19 \%$ del valor económico generado. Dentro de ellos, cabe destacar el jamón, categoría que, aún contando únicamente con seis denominaciones geográficas (4,26\% del total), aporta más del 14\% del valor económico conjunto. 


\subsection{Situación del sector del jamón con I.O.P.}

En España existen únicamente seis denominaciones geográficas de jamón: cinco D.O.P. (Jamón de Huelva ${ }^{2}$, Los Pedroches, Jamón de Teruel, Guijuelo y Dehesa de Extremadura), y una I.G.P. (Jamón de Trevélez). La situación dentro del sector del jamón con I.O.P. contrasta de forma importante con la situación de este producto más allá de las denominaciones geográficas, la cual destaca por una fuerte atomización de la producción, de modo que los diez primeros fabricantes suman sólo un 38\% de la producción (El Economista, 2008). En este sentido, hasta 1990 únicamente existían en nuestro país dos denominaciones geográficas, incorporándose en ese momento la tercera y, posteriormente, en 1995 una cuarta. Finalmente, en 2004 y 2005 se incorporarían Jamón de Trevélez y Los Pedroches, respectivamente, alcanzándose en dicho momento las seis denominaciones geográficas con las que el sector cuenta en la actualidad. La figura 2 muestra la evolución del número de I.O.P. de jamón en España desde 1987.

Figura 2

Número de I.O.P. de jamón en España (1987-2009)

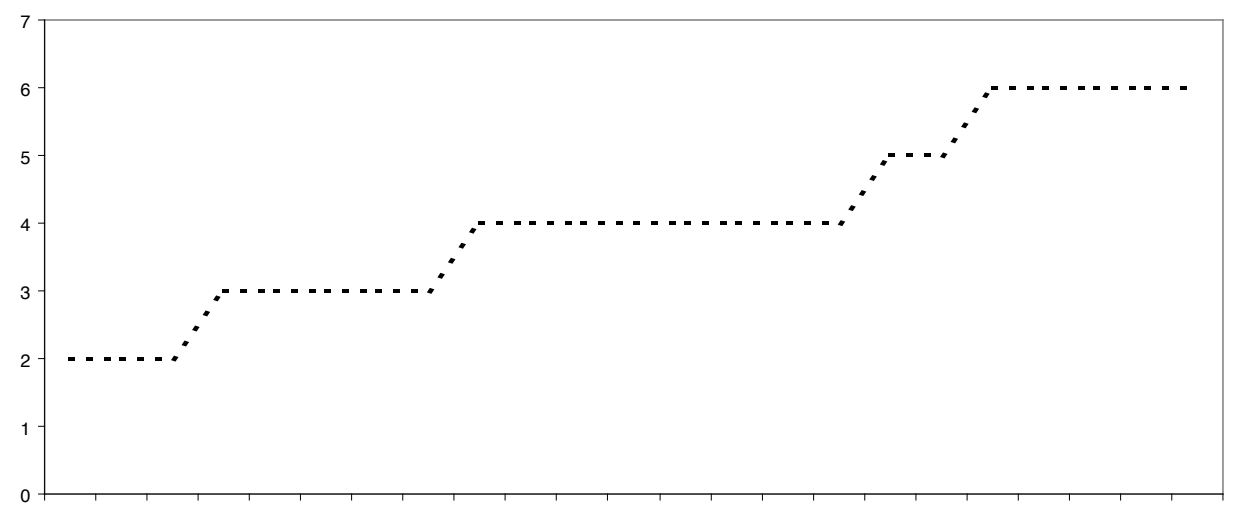

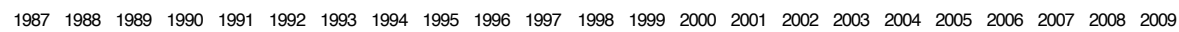

Fuente: Elaboración propia a partir de diversos informes del MARM

Como hemos comentado con anterioridad, a pesar de que el jamón es una de las categorías de producto agroalimentario que cuentan con un menor número de denominaciones, sus cifras de facturación son de las más importantes dentro del conjunto de las Denominaciones geográficas de nuestro país (véase figura 1). La figura 3 muestra la evolución del valor económico de la facturación del sector desde 1994 hasta 2008.

\footnotetext{
${ }^{2}$ Con fecha 7 de mayo de 2009 (B.O.E. núm. 111), el Ministerio de Medio Ambiente, Medio Rural y Marino aprobó la solicitud de modificación del nombre de la D.O.P. Jamón de Huelva por el de D.O.P. Jabugo
} 
Figura 3

Valor económico (millones de euros) de las I.O.P. de jamón en España (1994-2008)

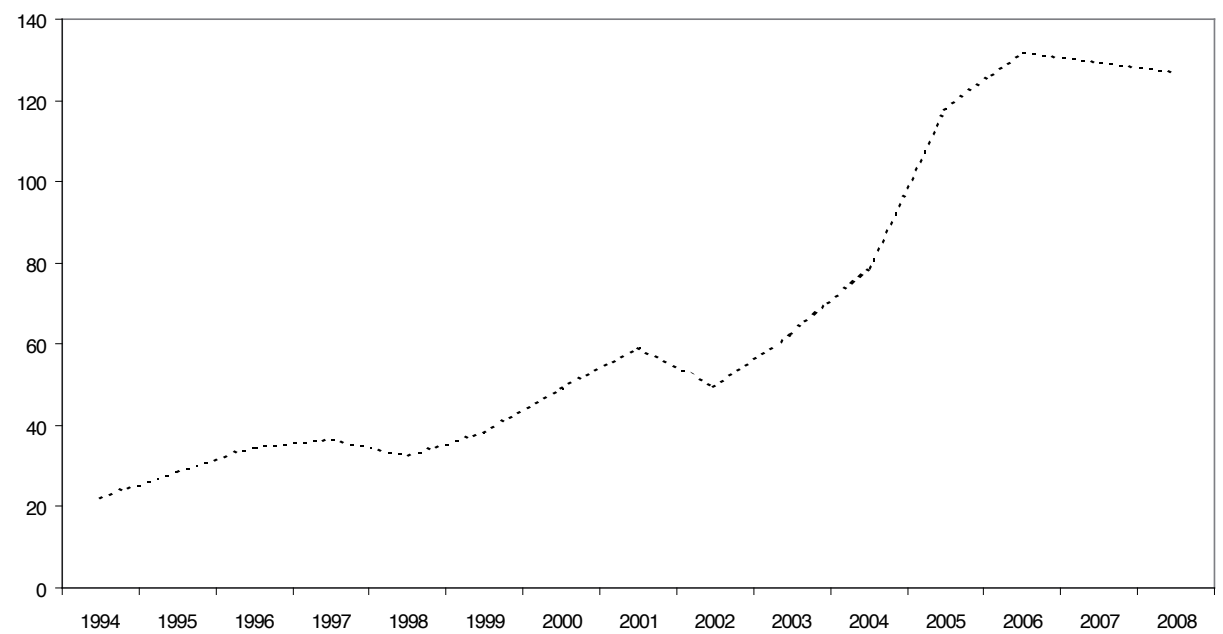

Fuente: Elaboración propia a partir de diversos informes del MARM

Como podemos observar en la figura 3, desde 1994 se observa un crecimiento relativamente constante de la facturación del conjunto de denominaciones geográficas de jamón, si bien desde 2004 el crecimiento se acentúa, al incorporarse las cifras de facturación de las dos últimas denominaciones establecidas (Los Pedroches y, especialmente, Jamón de Trevélez). En particular, Jamón de Trevélez comercializó entre 2004 y 2008 un total de 877.595 jamones $^{3}$ (véase tabla 2).

Tabla 2

Facturación $\left(n^{0}\right.$ de piezas $\left.{ }^{a}\right)$ de las I.O.P. de jamón en España (2001-2008)

\begin{tabular}{lcccccccc}
\hline \multicolumn{1}{c}{ I.O.P. } & 2001 & 2002 & 2003 & 2004 & 2005 & 2006 & 2007 & 2008 \\
\hline Jamón de Teruel & 285.131 & 293.242 & 341.678 & 97.495 & 427.632 & 474.150 & 474.476 & 490.724 \\
Guijuelo & 118.048 & 83.625 & 143.456 & 256.081 & 342.808 & 424.120 & 490.975 & 456.829 \\
Jamón de Huelva & 43.913 & 59.851 & 45.326 & 97.225 & 81.567 & 75.063 & 42.683 & 107.841 \\
Dehesa de Extremadura & 76.248 & 107.053 & 112.650 & 119.966 & 180.922 & 150.657 & 149.194 & 123.632 \\
Los Pedroches & - & - & - & - & 3.700 & 10.421 & 17.400 & 19.414 \\
Jamón de Trevélez & - & - & - & 63.720 & 122.014 & 256.311 & 238.794 & 196.756 \\
Total & $\mathbf{5 2 3 . 3 4 0}$ & $\mathbf{5 4 3 . 7 7 1}$ & $\mathbf{6 4 3 . 1 1 0}$ & $\mathbf{6 3 4 . 4 8 7}$ & $\mathbf{1 . 1 5 8 . 6 4 3}$ & $\mathbf{1 . 3 9 0 . 7 2 2}$ & $\mathbf{1 . 4 1 3 . 5 2 2}$ & $\mathbf{1 . 3 9 5 . 1 9 6}$ \\
\hline
\end{tabular}

Fuente: Elaboración propia a partir de diversos informes del MARM

${ }^{\text {aPaletas+jamones }}$

${ }^{3}$ Esta I.G.P. no comercializa paletas 
No obstante, en 2008 se observa un ligero descenso $(1,296 \%)$ en la facturación del conjunto de las Indicaciones Geográficas Protegidas, derivado de la contracción en el consumo provocada por la crisis económica. Aún así, existen tres I.G.P. (Jamón de Teruel, Jamón de Huelva y Los Pedroches) que experimentaron un crecimiento de sus cifras de comercialización. Especialmente destacable es el caso de la Indicación Jamón de Huelva que ha visto como, a pesar de la crisis económica, entre 2007 y 2008 su cifra de ventas se incrementó de forma espectacular en un 152,65\%, pasando de 42.683 piezas comercializadas en 2007 a 107.841 piezas en 2008. Es de esperar que, con el cambio de denominación aprobado, este incremento se mantenga e, incluso, aumente de forma importante, dado que el prestigio y la notoriedad del nombre Jabugo -tanto a nivel nacional como internacional- supera, en mucho, el conocimiento que el consumidor tiene del término Jamón de Huelva.

Figura 4

Cuota de mercado de las I.O.P. de jamón en España (2008) ( $\mathbf{n}^{0}$ de piezas)

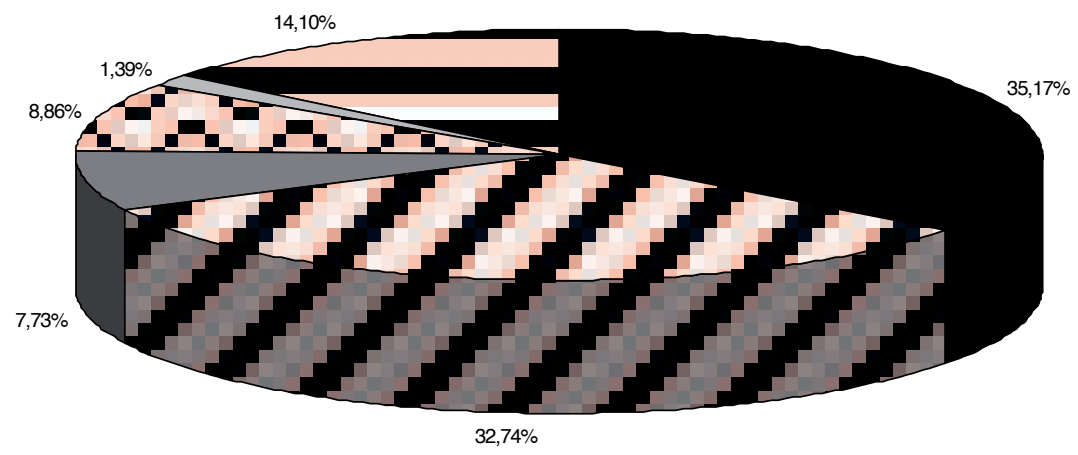

Jamón de Teruel $\square$ Guijuelo $\square$ Jamón de Huelva $\square$ Dehesa de Extremadura $\square$ Los Pedroches $\square$ Jamón de Trevélez

Fuente: Elaboración propia a partir de MARM (2009)

La figura 4 ilustra la cuota de mercado de cada una de las I.O.P. para el año 2008, con relación al número de piezas (jamón+paleta) comercializadas. Respecto al número de piezas, son la D.O.P. Guijuelo y Jamón de Teruel las que mayor cuota de mercado concentran (entre las dos aglutinan casi el $70 \%$ del número total de piezas comercializadas con Denominación geográfica en nuestro país (MARM, 2009). Cabe destacar la importante cuota que ostenta la Denominación Jamón de Trevélez (14,10\%), a pesar de ser- junto con la de Los Pedroches- la de más reciente creación. El valor de esta cifra es, incluso, mayor si tenemos además en cuenta que Jamón de Trevélez comercializa únicamente jamones pero no paletas.

La distribución de la cuota de mercado observada en la figura 4 guarda cierta similitud con los resultados obtenidos en el trabajo de Chamorro et al. (2008), en el que el 26\% 
de 382 individuos señalaban que la denominación geográfica que más conocen es la de Guijuelo. No obstante, y a diferencia de los niveles de cuota de mercado que aparecen representados en la figura 4, la segunda D.O.P. que los individuos encuestados señalaban como la más conocida era Dehesa de Extremadura (18\% de los encuestados). En términos de cuota de mercado, esta denominación ocupa la cuarta posición dentro del conjunto del sector. Otro de los resultados llamativos del trabajo de Chamorro et al. (2008) es que el consumidor no diferencia entre lo que es una D.O.P. o una I.G.P. En este sentido, estos autores señalan que el consumidor identifica los jamones con denominación geográfica con un producto de calidad contrastada y con un "producto para celebraciones especiales", pero no distingue entre ambos tipos de denominación ni, incluso, entre las diferencias entre los jamones que pueda haber entre las diferentes denominaciones geográficas. Así, por ejemplo, el consumidor desconoce que los jamones que proceden de la D.O.P. Jamón de Teruel y de la I.G.P. Jamón de Trevélez son jamones de cerdo blanco, y no ibérico. Esto indica que, la existencia de algún tipo de denominación que haga referencia al lugar del que procede el jamón es un indicador de calidad lo suficientemente importante por sí mismo, con independencia del número de fases del proceso productivo que, realmente, se desarrollen en la zona geográfica en cuestión 3/4diferencia entre los conceptos D.O.P. e I.G.P.3/4 y parece confirmar la importancia que tiene este elemento dentro de la estrategia de diferenciación de la empresa. De hecho, existe un segmento de mercado $3 / 4$ consumidores de nivel de renta alta que suelen adquirir los denominados productos delicatessen $3 / 4$ para los que la existencia de una garantía de calidad a través del origen del producto es un factor importante en su elección final, independientemente de otros aspectos relacionados con las características físico-químicas del producto (Chamorro et al., 2008).

Además del análisis de la cuota de mercado con relación al número de piezas vendidas, nos parece interesante hacer dicho análisis tomando como referencia el nivel de facturación y no el de piezas comercializadas. La tabla 3 y la figura 5 muestran esta información.

Tabla 3

Valor económico (millones de €) de las ventas de las I.O.P. de jamón en España (2001-2008)

\begin{tabular}{lcccccccc}
\hline \multicolumn{1}{c}{ I.O.P. } & 2001 & 2002 & 2003 & 2004 & 2005 & 2006 & 2007 & 2008 \\
\hline Jamón de Teruel & 17,14 & 17,62 & 20,53 & 7,02 & 30,79 & 34,14 & 36,06 & 37,30 \\
Guijuelo & 19,07 & 11,32 & 16,74 & 30,90 & 39,64 & 39,27 & 40,48 & 35,80 \\
Jamón de Huelva & 10,50 & 6,20 & 6,38 & 16,98 & 14,25 & 14,66 & 8,38 & 18,01 \\
Dehesa de Extremadura & 12,47 & 14,35 & 18,94 & 20,38 & 26,35 & 25,56 & 26,28 & 19,93 \\
Los Pedroches & - & - & - & - & 0,38 & 1,44 & 2,97 & 3,42 \\
Jamón de Trevélez & - & - & - & 3,37 & 6,45 & 16,40 & 15,28 & 12,59 \\
Total & 59,18 & 49,49 & 62,59 & 78,65 & 117,86 & 131,47 & 129,45 & 127,05 \\
\hline
\end{tabular}

Fuente: Elaboración propia a partir de diversos informes del MARM 
Figura 5

Cuota de mercado de las I.O.P. de jamón en España (2008) (sobre valor económico)

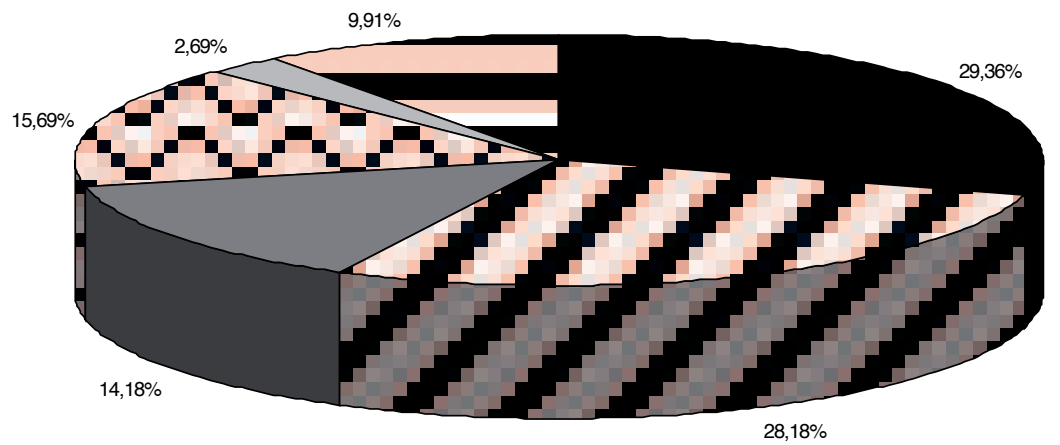

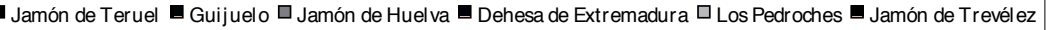

Fuente: Elaboración propia a partir de MARM (2009)

El análisis de la cuota de mercado en función del valor económico de la comercialización de cada una de las I.O.P. muestra algunos cambios con relación a la cuota que se puede observar en la figura 4. Así, el nivel de concentración de la cuota de mercado de las dos primeras denominaciones (Jamón de Teruel y Guijuelo) en términos de valor económico $(57,54 \%)$ es un $10,37 \%$ menor que en el caso de la cuota de mercado en términos de $\mathrm{n}^{\circ}$ de piezas $(67,91 \%)$. Igualmente, el porcentaje de cuota de mercado de Jamón de Trevélez en términos económicos $(9,91 \%)$ es un $4,19 \%$ menor que en términos de piezas comercializadas $(14,10 \%)$. Estos porcentajes son absorbidos por Jamón de Huelva y Dehesa de Extremadura, que ven como su cuota de mercado en términos económicos es un $6,45 \%$ y $6,83 \%$ superior a la cuota en términos de piezas comercializadas, respectivamente. Estos resultados son consecuencia de las diferencias que existen entre las diferentes denominaciones en términos de calidad y valor de sus productos, lo que se traduce en un precio de venta superior.

En particular, y en el caso de Jamón de Teruel y Jamón de Trevélez, la reducción de cuota de mercado en términos económicos en relación a la cuota que poseen en términos de número de piezas comercializadas se debe, fundamentalmente, al menor precio del jamón de cerdo blanco con relación al jamón de cerdo ibérico.

Finalmente, cabe destacar que el descenso total en el valor económico de las ventas de las I.O.P. de jamón en nuestro país fue de un 2,4\%, lo que supone un $1,10 \%$ más que el descenso en términos de número de piezas comercializadas $(1,289 \%)$. Este resultado pone de manifiesto que ha descendido más el precio que el consumidor paga por piezas con denominación de origen que el número adquirido de las mismas. 


\section{A. Mercado de destino de la producción de jamón de las I.O.P.}

El sector del jamón en España es un sector saturado. De hecho, en 2007 comenzó una contracción en el consumo importante que hizo reducir en un $20 \%$ las ventas. Sin embargo, esta evolución tan negativa no ha sido tan acusada en el caso de los jamones con denominación geográfica. En este sentido, como ya se ha comentado con anterioridad, el descenso en el número de piezas con denominación geográfica comercializadas entre 2007 y 2008 fue únicamente del 1,289\% en términos de cifra de ventas y del 2,4\% en términos de valor económico. Este resultado viene a confirmar el importante papel que juega el origen como herramienta de diferenciación del jamón, y la mayor importancia que toma en sectores tan saturados como este, en el que existe una importante atomización que hace, incluso, que sea difícil disponer de estadísticas y datos fiables (Expansión, 2009a).

La mayor parte de la comercialización de estas marcas se realiza en el mercado nacional, si bien de forma progresiva, los mercados exteriores -tanto el resto de países de la UE, como terceros países (e.g., EE.UU., Japón, Canadá, etc.), están tomando un protagonismo cada vez mayor en estas cifras. En la tabla 4 se muestra la distribución geográfica de las ventas de jamón durante 2008 de las seis I.O.P. de jamón existentes en España, en número de piezas y millones de euros.

Tabla 4

\section{Distribución geográfica de las ventas del conjunto de Denominaciones de jamón existentes en España [n ${ }^{0}$ de piezas (mill. $\left.\left.€\right)\right]$ (año 2008)}

\begin{tabular}{|c|c|c|c|c|}
\hline & MERCADO NACIONAL & U.E. & TERCEROS PAÍSES & TOTAL \\
\hline Jamón de Teruel & $490.724(37,30)$ & - & - & $490.724(37,30)$ \\
\hline Guijuelo & $411.146(32,22)$ & $\begin{array}{l}31.978 \\
(2,51)\end{array}$ & $13.705(1,07)$ & $456.828(35,80)$ \\
\hline Jamón de Huelva & $107.841(18,01)$ & - & - & $107.841(18,01)$ \\
\hline Dehesa de Extremadura & $75.563(15,83)$ & n.d. & n.d. & $123.632(19,93)$ \\
\hline Los Pedroches & n.d. & n.d. & - & $19.414(3,42)$ \\
\hline Jamón de Trevélez & $177.080(11,33)$ & $\begin{array}{l}11.805 \\
(0,76)\end{array}$ & $7.871(0,50)$ & $196.756(12,59)$ \\
\hline Total & $1.310 .423(114,69)$ & $\begin{array}{c}43.783 \\
(3,27)\end{array}$ & $21.575(1,57)$ & $\begin{array}{l}1.395 .196 \\
\left(127,051^{4}\right)\end{array}$ \\
\hline
\end{tabular}

Fuente: MARM (2009) n.d. (no disponible)

La figura 6 muestra la distribución porcentual de las ventas (respecto al $\mathrm{n}^{\mathrm{o}}$ de piezas y a su valor económico) del conjunto de Denominaciones de jamón existentes en España en 2008.

\footnotetext{
${ }^{4}$ La cifra resultante de sumar los totales por Denominación y zona geográfica (1.375.781 piezas y 119,53 millones de euros) no coincide con el resultado de la tabla (1.395.196 y 127,05, respectivamente), dado la no disponibilidad de datos de las ventas por zona geográfica para todas las Denominaciones de jamón
} 
Como podemos observar, el mercado nacional es el principal objetivo de algunas de las I.O.P. Así, las D.O.P. Jamón de Huelva y Jamón de Teruel únicamente comercializan sus piezas en el mercado nacional; por el contrario, Guijuelo, Jamón de Trevélez, Los Pedroches y Dehesa de Extremadura (de estas dos últimas denominaciones no hay información disponible en este sentido) sí que destinan parte de su producción al mercado exterior.

En este sentido, para el caso de terceros países, podemos observar como Guijuelo es la Denominación geográfica que mayor cuota de mercado posee en los mercados exteriores (73\% y $63 \%$ de las ventas totales en la UE y terceros países, respectivamente -número de piezas comercializadas, y $76 \%$ y $68 \%$-valor económico). Jamón de Trevélez es la que posee el resto de la cuota de mercado en el caso de terceros países (37\% -número de piezas- y 32\% -valor económico), siendo menor su participación (27\% y 23\%) en las ventas en la UE5

Respecto al mercado nacional (número de piezas), este se encuentra dominado por las D.O.P. Jamón de Teruel y Guijuelo, que aglutinan el $70 \%$ ( ${ }^{\circ}$ de piezas) y el $60 \%$ (valor económico) eñ de la cuota de mercado.

\section{Figura 6}

Distribución porcentual por mercado de destino de las ventas ( $n^{0}$ de jamones y valor económico) del conjunto a de Denominaciones de jamón existentes en España (año 2008)

\section{NÚMERO DE JAMONES}
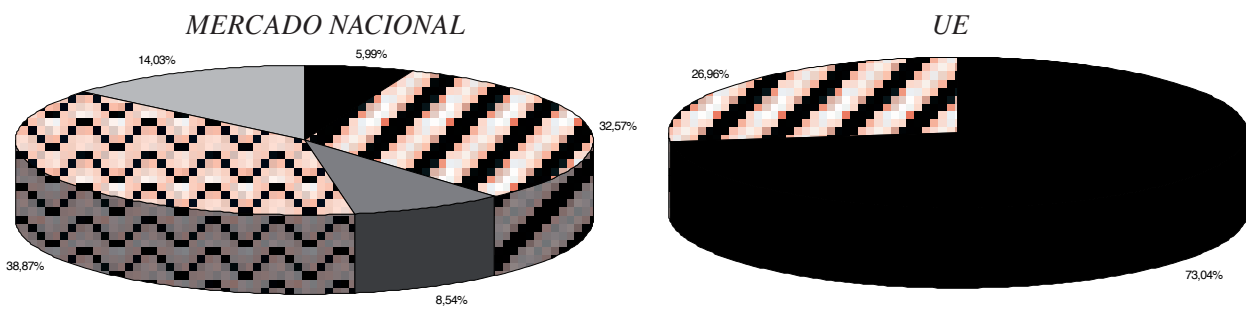

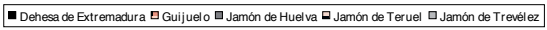
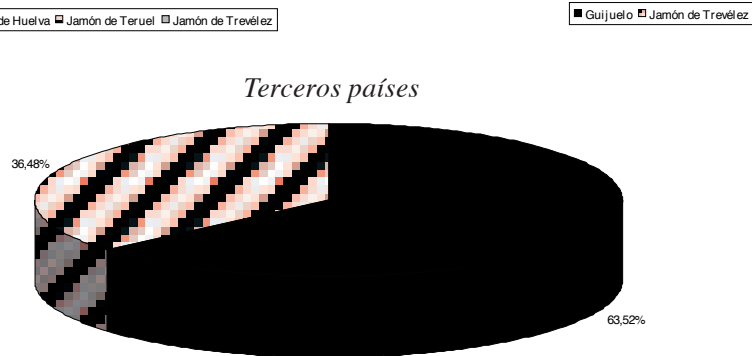

- Guijuelo ت Jamón de Trevélez

\footnotetext{
${ }^{5}$ Estas cifras no tienen en cuenta las ventas de Dehesa de Extremadura en el caso de las ventas a terceros países, y Dehesa de Extremadura y Los Pedroches en el caso de la UE, dada la no disponibilidad de información por mercado de destino para estas dos denominaciones
} 


\section{VALOR ECONÓMICO}

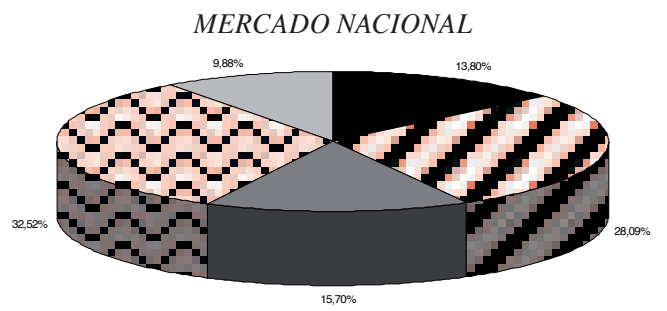

- Dehesa de Extremadura $\square$ Guijuelo $\square$ Jamón de Huel va $\square$ Jamón de Teruel $\square$ Jamón de Trevélez

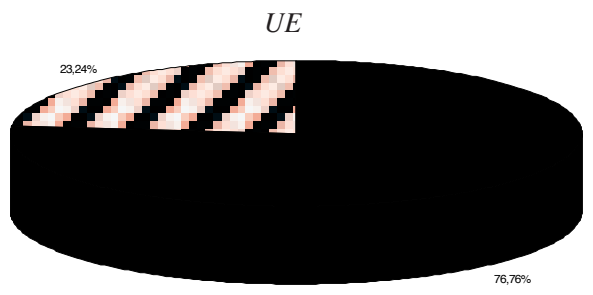

- Guijuelo Đ Jamón de Trevélez

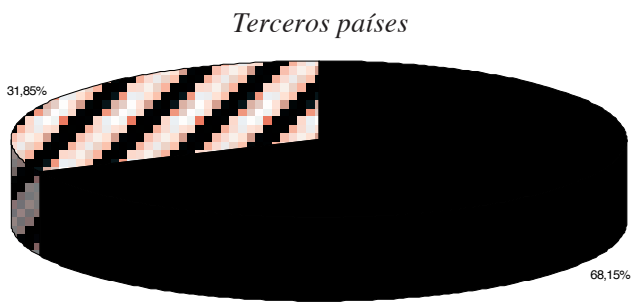

- Guijuelo घ Jamón de Trevélez

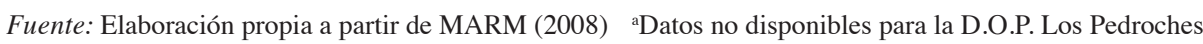

El hecho de que sean pocas las denominaciones que comercializan su producción en mercados exteriores se debe a los problemas sanitarios que los productos derivados del cerdo han tenido -y, en muchos casos, siguen teniendo- en muchos de estos mercados (e.g., China, EE.UU. y, recientemente, Rusia). Si a esto le unimos la dificultad para desarrollar canales de distribución en los mercados exteriores y los diferentes hábitos de consumo que existen respecto a este producto ${ }^{6}$, podemos observar la existencia de un elevado número de barreras a la exportación del jamón.

No obstante, la posición en los mercados exteriores está permitiendo a denominaciones como Jamón de Trevélez, incrementar su nivel de beneficios en dichos mercados, para, con los recursos procedentes de dichos beneficios, encarar una estrategia de mayor desarrollo y presencia en el mercado nacional. Y es que es necesario tener en cuenta que la competencia en el mercado nacional es altamente costosa, derivado de la atomización del sector, el mayor conocimiento que del producto tiene el consumidor nacional 3/4con relación al consumidor extranjero, y, en el caso particular de Jamón de Trevélez, los elevados costes de aprovisionamiento y transporte.

\footnotetext{
${ }^{6}$ En muchos países el consumo de jamón no está bien visto, lo que supone un freno importante a la exportación. Es el caso, por ejemplo, de China, donde a muchos habitantes no les gusta el jamón porque les parece que está crudo
} 


\section{B. Tendencia del mercado: análisis DAFO y previsión de ventas}

Para finalizar vamos a establecer las principales oportunidades y amenazas que se presentan en el sector, las fortalezas que las I.O.P. deben desarrollar para aprovecharlas, así como los aspectos que pueden suponer un mayor problema para el desarrollo de la actividad competitiva. Adicionalmente, completaremos este análisis del sector con una previsión La tabla 5 muestra el análisis DAFO del sector del jamón en nuestro país.

Las principales amenazas del sector se derivan de la reducción de la demanda como consecuencia de la contracción del consumo experimentada desde finales de 2007. En particular, la contención del consumo se ha expresado de forma más intensa en el canal HORECA (Hostelería, Restauración y Cafetería). Igualmente, la imposición de normas y requisitos de calidad (sobre todo en los mercados exteriores), hacen necesario el desarrollo de fuertes inversiones que permitan cumplir con dichas exigencias. Por otra parte, y desde la perspectiva del consumidor, existe, en muchos casos, un desconocimiento acerca de las diferentes denominaciones geográficas que existen en nuestro país. Esto hace necesario que los Consejos Reguladores de cada una de las denominaciones deban desarrollar estrategias de diferenciación que le permitan distinguirse de sus competidores. En este sentido, el propio origen es el elemento clave sobre el que debe girar el desarrollo de dicha estrategia.

Tabla 5

Análisis DAFO del sector del jamón en España (2009)

\begin{tabular}{|c|c|}
\hline Debilidades & Amenazas \\
\hline $\begin{array}{l}\text { - Exceso importante de oferta. En España "sobran" } \\
\text { un millón de jamones ibéricos, lo que ha provocado } \\
\text { que los precios caigan. Así por ejemplo, el precio } \\
\text { de venta al público del jamón o paleta ibérica de } \\
\text { cebo se ha desplomado un } 50 \% \text { desde } 2007 \\
\text { - Congelación de producto. Si bien no es reconocido } \\
\text { por los industriales, muchos de ellos han tenido } \\
\text { que congelar el producto que procede de animales } \\
\text { criados entre } 2006 \text { y 2007, fecha en la que el precio } \\
\text { de las materias primas estaba disparado. El objetivo } \\
\text { es esperar a que la situación económica mejore para } \\
\text { poder obtener rentabilidad de dicha producción } \\
\text { - Elevado coste de distribución a determinados } \\
\text { mercados (EE.UU., China, Japón) } \\
\text { - Escasa capacidad de comunicación de las diferen- } \\
\text { cias entre Denominaciones de Origen (D.O.P.) e } \\
\text { Indicaciones Geográficas Protegidas (I.G.P.) } \\
\text { - Excesiva atomización del sector }\end{array}$ & $\begin{array}{l}\text { - Contención del consumo de los hogares y de las } \\
\text { ventas al canal HORECA, consecuencia de la } \\
\text { crisis económica } \\
\text { - Modificación de la Norma de Calidad del Ibérico. } \\
\text { En particular, se pretende que las categorías bellota } \\
\text { y recebo se analicen por separado y no pueda haber } \\
\text { cruces entre ellas, de modo que no se pueda hacer } \\
\text { pasar cerdos de recebo por animales de bellota } \\
\text { - Imposición de normas y frenos a la exportación. Es } \\
\text { el caso del mercado chino, que exige a los países } \\
\text { exportadores de derivados porcinos que acrediten } \\
\text { que los animales estaban sanos antes del sacrificio } \\
\text { - Hábitos socioculturales y de alimentación diferen- } \\
\text { tes. En muchos países, el consumo de jamón no } \\
\text { está bien visto, lo que supone un freno importante } \\
\text { a la exportación. Es el caso, por ejemplo, de China, } \\
\text { donde a muchos habitantes no les gusta el jamón } \\
\text { porque les parece que está crudo } \\
\text { - Escasa formación del consumidor. En muchos } \\
\text { casos, el consumidor no tiene clara las diferencias } \\
\text { entre los diferentes tipos de jamón, de modo que } \\
\text { confunde, por ejemplo, un ibérico 100\% puro de } \\
\text { bellota de un ibérico fabricado en explotación in- } \\
\text { tensiva, o un jamón de cerdo blanco con un ibérico } \\
\text { - Epidemias y enfermedades relacionadas con el } \\
\text { porcino } \\
\text { - Hábitos de consumo menos saludables ('comida } \\
\text { basura') }\end{array}$ \\
\hline
\end{tabular}




\begin{tabular}{ll}
\hline \multicolumn{1}{c}{ Fortalezas } & \multicolumn{1}{c}{ Oportunidades } \\
\hline - Fuerte posicionamiento del jamón de bellota: $\mathrm{Si}$ & \\
bien es cierto que se ha producido un descenso & Utilización del jamón como reclamo promocional. \\
en el precio de los jamones de menor categoría, & Las agencias de viajes, por ejemplo, han cambiado \\
el más exclusivo-el ibérico puro de bellota- está & sus tradicionales maletas de regalo por jamones de \\
manteniendo los precios, consecuencia de un mejor & pata negra, consecuencia de la sobreproducción. \\
posicionamiento & - Consolidación de nuevos mercados: la consoli- \\
- Calidad diferenciada y certificación: la certifica- & dación del consumo en mercados como Japón, \\
ción hace que el producto tenga gran aceptación, & EE.UU. o China va a permitir incrementar el nivel \\
sea conocido y demandado, lo que ha permitido & de exportaciones (se estima que en 2009 las expor- \\
$\begin{array}{l}\text { que el descenso del consumo no se haya acusado } \\
\text { tanto en las DOP y en las IGP }\end{array}$ & taciones rondaron los 230 millones de euros, lo que \\
- Mayor consolidación de los canales de distribución & supone una participación sobre la producción total \\
electrónicos: el caso de la I.G.P. Jamón de Trevélez & en torno al 9,5\%) \\
es un buen ejemplo de la importancia que están & - Imagen positiva de la denominada 'dieta medite- \\
tomando estos canales en la distribución de jamón & rránea' \\
- Sector consolidado y con tradición en nuestro país & \\
\hline
\end{tabular}

Fuente: Elaboración propia a partir de Expansión (2009a) y El Economista (2009)

En este contexto, cada una de las denominaciones está posicionando su oferta a partir de diferentes atributos; por ejemplo, Jamón de Trevélez se centra en la posesión de un nivel de grasa "natural" que le permite permanecer más tiempo en curación y poseer, por tanto, un menor nivel de sal, consecuencia -entre otros aspectos- de la altura de la región de procedencia ${ }^{7}$.

Por su parte, Jamón de Huelva explota el mayor conocimiento que el individuo tiene de aquella zona gracias al jamón de Jabugo. De hecho, la D.O.P. Jamón de Huelva consiguió el 7 de mayo de 2009 que el Ministerio de Medio Ambiente y Medio Rural diera publicidad al cambio de denominación por el de Jabugo, gracias, principalmente, al acuerdo al que el Consejo Regulador de Jamón de Huelva llegó con el Ayuntamiento de Jabugo con objeto de proteger el jamón tradicional elaborado en la Sierra de la provincia de Huelva. No obstante, durante un tiempo se mantendrá la denominación Jamón de Huelva en las piezas comercializadas en aquella zona del oeste de Andalucía.

Respecto a las oportunidades que presenta el sector, cabe destacar el buen posicionamiento de la 'dieta mediterránea', la consolidación de los mercados exteriores (fundamentalmente China, Japón y EE.UU.) y la utilización del jamón como reclamo promocional, lo que puede permitir derivar a través de ese medio parte del excedente que pueda existir en cada caso.

Las condiciones del sector para aprovechar todas las oportunidades anteriores y hacer frente a las amenazas existentes no son del todo positivas. En este sentido, la atomización del sector es muy elevada, lo que ha provocado -junto con la caída del consumo- un exceso de oferta que ha provocado una importante caída de precios. Esta caída de precios ha provocado que muchos productores hayan optado por congelar piezas que proceden de 2006 y 2007, momento en el que la materia prima tenía un precio mucho más elevado y en el que el precio de los jamones era suficiente para compensar dichos costes. Si bien esta es

\footnotetext{
${ }^{7}$ Trevélez, en la provincia de Granada, es el pueblo más alto de España
} 
una práctica no reconocida por los productores, sí parece que se esté produciendo. Además, los mercados exteriores como salida para la saturación del mercado nacional no parecen sencillos de alcanzar, dados los elevados costes estructurales necesarios para poder llegar a ellos. Finalmente, y como consecuencia del exceso de oferta, es complicado comunicar las diferencias entre tipos de jamón y marcas al consumidor final; en este sentido, el origen vuelve a convertirse en una herramienta fundamental para diferenciar, que es necesaria potenciar, ya que la certificación hace que el producto tenga gran aceptación, sea conocido y demandado. A nuestro juicio, esta ha sido la principal razón por la que el descenso del consumo no ha sido tan acusado en el ámbito de las I.O.P. como a nivel general del sector.

Con objeto de completar el análisis DAFO presentado en los párrafos anteriores, vamos a realizar una estimación de las ventas futuras del sector para el período 2010-2015. Para ello, utilizaremos la información contenida en la tabla 2, en la que se muestra la evolución de la facturación (en número de piezas) entre 2001 y 2008 para cada una de las Denominaciones y para el total del sector. La representación gráfica de esta información se muestra en la figura 7.

\section{Figura 7}

Evolución de la facturación ( $n^{0}$ de piezas) del conjunto ${ }^{a}$ de Denominaciones de jamón existentes en España (2001-2008)

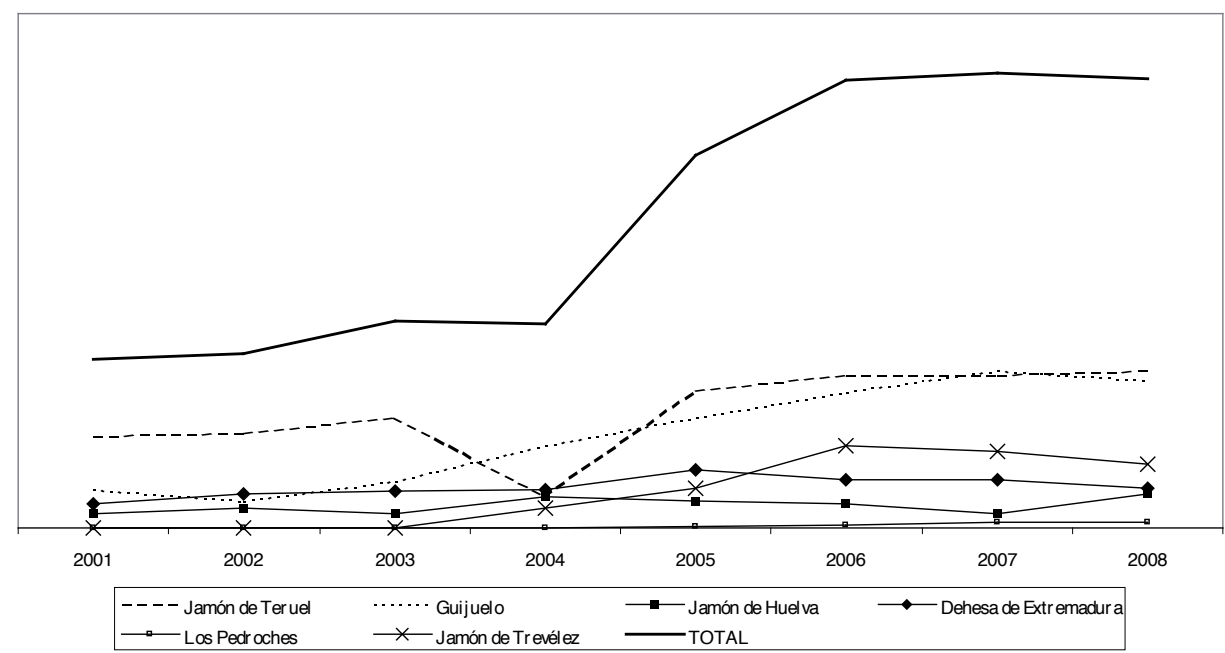

${ }^{a}$ La facturación de Jamón de Trevélez comienza en 2004 y la de los Pedroches en 2005

Como podemos observar en la figura 7 , la evolución en la facturación de cada una de las Denominaciones entre 2001 y 2008 ha sido muy diferente. En este sentido, la evolución de la facturación de Jamón de Teruel es totalmente diferente a la del resto de Denominaciones, con un descenso importante en 2004. En el resto de Denominaciones se observa una tendencia mucho más estable con movimientos a lo largo de los años menos bruscos. Dado 
que Jamón de Teruel es el líder del sector (véase figura 4) y que su evolución en las ventas muestra un comportamiento muy particular, vamos a analizar la evolución de las cifras de facturación del sector sin tener en cuenta la información de esta Denominación. La figura 8 muestra la evolución de las ventas del sector considerando todas las Denominaciones y excluyendo la facturación de Jamón de Teruel.

Figura 8

Evolución de la facturación ( $n^{0}$ de piezas) del conjunto a de Denominaciones de jamón existentes en España y excluyendo Jamón de Teruel (2001-2008)

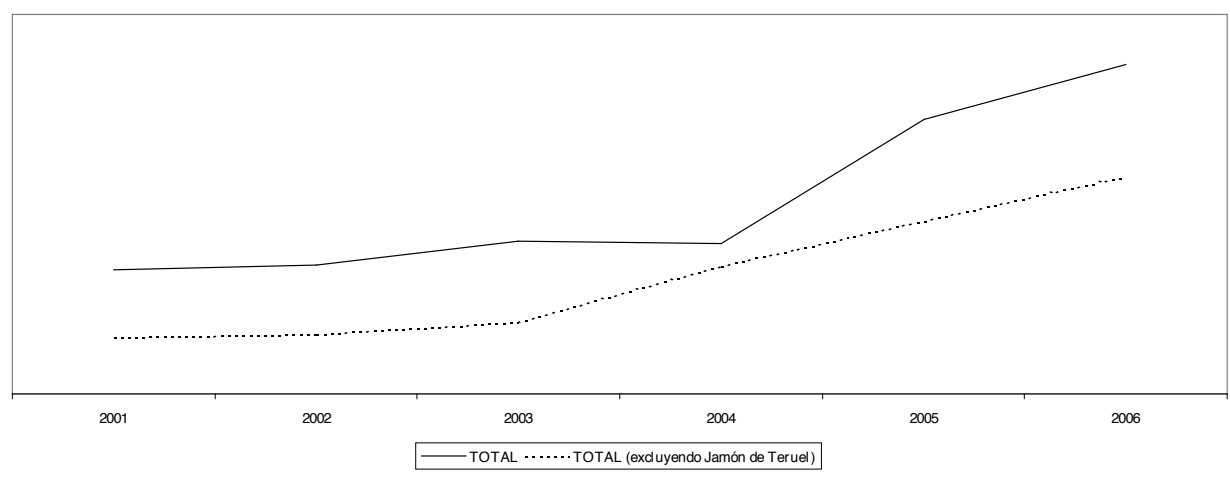

a La facturación de Jamón de Trevélez comienza en 2004 y la de los Pedroches en 2005

Como podemos observar en la figura 8, la evolución de la facturación de Jamón de Teruel ha tenido durante el período 2001-2008 una fuerte influencia en las cifras de venta del sector. En este sentido, la evolución de la facturación del sector excluyendo las cifras de Jamón de Teruel muestran un crecimiento relativamente estable, mientras que cuando tenemos en cuenta la evolución particular de Jamón de Teruel observamos cómo se repite ese brusco descenso en 2004 característico de la evolución de las cifras de facturación de esta Denominación. Es por ello que, con objeto de realizar una estimación de las ventas futuras del sector lo más fiable posible, tendremos en cuenta, por una parte la evolución de las ventas para el conjunto de denominaciones excluyendo Jamón de Teruel, y por otra la evolución particular de la cifra de ventas de esta última. A partir de ahí, la previsión de ventas del sector se realizará como la suma de las cantidades que resulten de ambas estimaciones. No obstante, y con objeto de comprobar la validez de esta estimación, se realizará una previsión de las ventas del sector teniendo en cuenta la totalidad de denominaciones existentes en el sector. Para la estimación de las ventas futuras del sector se utilizará la metodología de las series temporales.

Una serie temporal -también llamada serie cronológica o histórica, puede definirse como una sucesión de observaciones de una variable en distintos momentos del tiempo (Uriel y Muñiz, 1993). Básicamente, lo que se pretende con el estudio de las series temporales es el conocimiento de una variable a través del tiempo para, a partir de este conoci- 
miento, y bajo el supuesto de que no se van a producir cambios estructurales, poder realizar predicciones (Jiménez et al., 2006). Es, por tanto, la estabilidad temporal del conjunto de factores causales que operan sobre la variable dependiente el elemento clave sobre el que se articulan las predicciones a través de series temporales (Wilson et al., 2000).

El análisis de las series temporales proporciona una solución ideal para el tratamiento de una serie de datos que se encuentren correlacionados (Harvey, 1993). Su uso se encuentra ampliamente difundido en múltiples ámbitos, así como en sectores de muy diversa naturaleza (e.g., Chatfield, 1989; Kao y Huang, 2000), demostrándose su validez predictiva y su utilidad en la ayuda para la toma de decisiones (Zou y Yang, 2004). Ello es debido, principalmente, a que las predicciones a corto plazo que proporciona el análisis de series temporales sirve como un excelente complemento a la información estadística de la que dispone la empresa, ya que esta información se suele obtener de modo diferido y con cierto retraso, dificultando la toma de decisiones por parte de la empresa hasta que esta información pueda estar disponible (Otero y Trujillo, 1998).

La estimación de las tres series temporales planteadas (total sector, sector excluyendo Jamón de Teruel y Jamón de Teruel) se ha realizado con el suplemento StatTools de Excel. La tabla 6 muestra el resultado de la previsión de los tres modelos para el período 20102015, así como el coeficiente de determinación de cada ajuste.

Tabla 6

Previsión de facturación ( $\mathrm{n}^{0}$ de piezas) para los tres modelos estimados (2010-2015) y coeficiente de determinación

\begin{tabular}{|c|c|c|c|c|c|c|c|}
\hline & \\
\hline & 2010 & 2011 & 2012 & 2013 & 2014 & 2015 & $\mathrm{R}^{2}$ \\
\hline Total sector (1) & $1.397 .935,12$ & $1.406 .439,46$ & $1.439 .558,43$ & $1.522 .548,31$ & $1.603 .005,24$ & $1.723 .684,94$ & 0,4620 \\
\hline Jamón de Teruel (2) & $574.839,32$ & $668.831,44$ & $725.739,12$ & $762.860,68$ & $790.221,02$ & $803.002,18$ & 0,6341 \\
\hline $\begin{array}{l}\text { Total sector (excluyendo } \\
\text { Jamón de Teruel) (3) }\end{array}$ & $931.584,31$ & $946.432,41$ & $960.593,79$ & $986.753,33$ & $1.008 .437,2$ & $1.041 .432,94$ & 0,8405 \\
\hline $\begin{array}{l}\text { PREVISIÓN TOTAL } \\
\text { DEL SECTOR }(2+3)\end{array}$ & \multicolumn{7}{|c|}{$1.506 .423,631.615 .263,851.686 .332,911.749 .614,011.798 .658,221.844 .435,12$} \\
\hline
\end{tabular}

Como podemos observar, la estimación realizada para el conjunto del sector sin incluir la cifra de facturación de la denominación Jamón de Teruel ofrece resultados mucho más fiables que la que se realiza teniendo en cuenta el conjunto de Denominaciones, tal y como pone de manifiesto el mayor valor del coeficiente de determinación en el primero de los casos $(0,8405)$ frente al segundo $(0,4620)$. Si además tenemos en cuenta que el coeficiente de determinación de la serie temporal estimada para Jamón de Teruel de forma particular es, igualmente, elevado $(0,6341)$, la previsión de ventas del sector como suma de la cifra de esta última y la del resto del sector, se presenta como la más fiable desde el punto de vista estadístico. Las previsiones realizadas son, en general, optimistas, dado que para este año 2010 se prevén unas ventas en el sector de 1.506.423 piezas. Es cierto que esta cifra supondría únicamente unas 110.000 piezas más que las que se facturaron en 2008 , pero lo importante es que supondría volver a la tendencia creciente que se rompió entre 2007 y 
2008 con un descenso de las ventas del sector del 1,29\%. A partir de la recuperación en la tasa de crecimiento que supone la cifra de ventas prevista para 2010, se observa una evolución creciente y constante hasta el año 2015 lo que parece indicar que el sector del jamón con denominación en España va a superar de forma positiva las consecuencias derivadas de la crisis económica y que sí parece que van a tener mayor repercusión en el conjunto del sector sin denominación de origen. La tabla 7 muestra la evolución en la previsión de ventas del sector para el período 2010-2015 en términos porcentuales.

Tabla 7

Previsión de facturación ( $n^{0}$ de piezas e incremento porcentual) para el sector del jamón con denominación de origen para el período 2010-2015

\begin{tabular}{lcccccc}
\cline { 2 - 6 } & 2010 & 2011 & 2012 & 2013 & 2014 & 2015 \\
\hline $\mathrm{N}^{\mathrm{o}}$ de piezas & $1.506 .423,63$ & $1.615 .263,85$ & $1.686 .332,91$ & $1.749 .614,01$ & $1.798 .658,22$ & $1.844 .435,12$ \\
\hline Incremento (\%) s/año anterior & $7,972^{\mathrm{a}}$ & 7,225 & 4,400 & 3,753 & 2,803 & 2,545 \\
\hline Incremento medio (\%) (2010-2015) & \multicolumn{5}{c}{4,783} \\
\hline
\end{tabular}

a Sobre cifra de ventas real de 2008

Como podemos observar en la tabla 7, la tasa media anual de crecimiento de las ventas del sector para el período 2010 y 2015 es de 4,783\%. No obstante, y si bien es cierto que las ventas del sector crecerán, efectivamente, año a año, no es menos cierto que lo harán cada vez a un ritmo menor. En este sentido, mientras que el período comienza con tasas de crecimiento superiores al 7\%, los últimos dos años finaliza con tasas inferiores al 3\%. A pesar de ello, a nuestro juicio las perspectivas para el sector del jamón con denominación en nuestro país parecen optimistas, mucho más teniendo en cuenta que el sector alimenticio en general y el cárnico en particular son los que están sufriendo las consecuencias más graves de la crisis económica (Expansión, 2009b).

\section{CONCLUSIONES}

La vinculación con un origen determinado es una de las estrategias competitivas más utilizadas por parte de muchos productos agroalimentarios. Productos como el vino o el queso son ejemplos de una intensa utilización del origen en beneficio del producto amparado bajo el mismo. En el caso del jamón, la utilización del origen como elemento diferenciador es relativamente reciente y tiene una "explotación" mucho menor que la mayor parte de productos agroalimentarios, tal y como demuestra el hecho de que en un país como España, cuna del jamón, existan únicamente seis denominaciones geográficas. No obstante, a pesar del reducido número de I.O.P. que existen en este sector, el origen parece configurarse como un elemento competitivo clave, dado que la situación del conjunto de denominaciones geográficas de jamón existentes en nuestro país ha sido en los últimos años muy positiva, aún cuando el sector en general comenzó a sufrir descensos importantes 
del consumo desde finales de 2006 y comienzos de 2007. En este sentido, hemos puesto de manifiesto el importante papel que el origen parece estar jugando en la comercialización del jamón, tanto en nuestro país como en los mercados exteriores. Así lo ponen de manifiesto la evolución de las cifras de facturación del sector en los últimos años, en particular en 2007 y 2008, donde el descenso de la facturación ha sido prácticamente inapreciable, mucho menor que el que se produjo en el conjunto del sector del jamón sin denominación de origen. Incluso, la previsión de facturación del conjunto de denominaciones de jamón para los próximos cinco años registra tasas medias de crecimiento entorno al $5 \%$.

No obstante, y puesta de manifiesto la utilidad del origen como elemento diferenciador, creemos necesario realizar una reflexión acerca de la utilización de las I.O.P. por parte de los productos agroalimentarios. En la medida en la que el origen no sea identificado, reconocido y valorado por parte del consumidor, aquel perderá su razón de ser (Cambra y Villafuerte, 2009).

Reconociendo el papel que la I.O.P. juega en el reconocimiento y vinculación de un determinado producto de calidad con su origen, creemos que dentro del mercado español de productos agroalimentarios en general y el jamón en particular, las I.O.P. no están cumpliendo plenamente las funciones para las que fueron inicialmente creadas. Esta opinión es compartida por Cambra y Villafuerte (2009), en el análisis que realizan de las I.O.P. a nivel general en España. Para estos autores, gran parte del incumplimiento de estas funciones se debe a la escasa inversión en imagen de marca de las I.O.P. por parte de los Consejos Reguladores y de las empresas que la integran. No obstante, es cierto que -en particular en el sector del jamón- algunas de las denominaciones están desarrollando un importante esfuerzo en comunicación para potenciar y dar a conocer su origen, sobre todo las que destinan parte de su producción a los mercados exteriores (e.g., Guijuelo) o las que, por su procedencia, pueden llegar a ser más desconocidas por parte del consumidor (e.g., Jamón de Trevélez).

Otro de los problemas que está emergiendo $3 / 4$ especialmente en productos como los quesos o el aceite de oliva virgen, donde existen 24 denominaciones en cada caso $3 / 4$ es la dificultad para reconocer y valorar las distintas indicaciones por parte del consumidor. Esta atomización hace que en ocasiones el consumidor solo sea capaz de decidir entre la compra de un producto protegido frente a uno que no lo está, pero que no sea capaz de distinguir entre el conjunto de aquellos (Cambra y Villafuerte, 2009).

Igualmente, se pueden producir efectos derivados de la existencia de Denominaciones con diferentes años de vida. Este problema 3/4denominado por Cambra y Villafuerte (2009) como "banalización" $3 / 4$ puede producir que un consumidor piense que todas las marcas que ampara una determinada I.O.P. son de peor calidad, únicamente por el hecho de que pertenezcan a una denominación menos consolidada que otras con mayor tradición. Esta situación puede obligar a aquellas I.O.P. con menor notoriedad y penetración en el mercado a desarrollar estrategias de marketing que permitan un mayor (y más rápido) conocimiento por parte del consumidor. Un claro ejemplo lo encontramos en el sector del jamón. Denominaciones relativamente recientes (e.g., Jamón de Trevélez), con un nivel de notoriedad y de conocimiento en el mercado mucho menor que Denominaciones consolidadas como Guijuelo, han logrado incrementar su presencia en el mercado nacional y exterior gracias al desarrollo de su portal de comercialización on-line.

A modo de resumen, queremos resaltar la importancia que el origen puede tener en la estrategia competitiva de los productos agroalimentarios, si bien es necesario, para ello, 
el desarrollo de acciones que vayan encaminadas a potenciar el origen y facilitar al consumidor la identificación del mismo. En este sentido, creemos necesario que se destinen mayores recursos a la construcción del "capital de marca-origen", a través de herramientas de comunicación directa e indirecta que permitan incrementar la notoriedad del origen y permitan utilizar este último como elemento decisor en los procesos de elección del consumidor.

\section{REFERENCIAS BIBLIOGRÁFICAS}

AHMED, Z., JONSON, J., YANG, X., FATT, K., TENG, H. Y BOON, L. (2004): «Does country of origin matter for low involvement products? », International Marketing Review, Vol. 21, pp. 102-120.

AL-SULAITI, K. Y BAKER, M. (1998): «Country of origin effects: a literature review”, Marketing Intelligence and Planning, Vol. 16, No. 3, pp. 150-199.

BALABANIS, G. Y DIAMANTOPOULOS, A. (2008): «Brand origin identification by consumers: a classification perspective», Journal of International Marketing, Vol. 16, No. 1, pp. 39-71.

BARCO, E. (2007): «Denominaciones de origen. La incidencia de la localización y deslocalización», Distribución y Consumo, Vol. 96 pp. 27-39.

BERTOZZI, L. Y PANARI, G. (1993): «Cheeses with appellation d'Origine Contrôlée (AOC): factors that affect quality», International Dairy Journal, Vol. 3, pp. 297-312.

BLACKWELL, R., MINIARD, P. Y ENGEL, J. (2006): Consumer Behavior, $10^{\text {th }}$ ed., Aufl., Mason.

CALDENTEY, P. Y GÓMEZ, A. C. (1996): «Productos Típicos, Territorio y Competitividad», Agricultura y Sociedad, Vol. 80-81, pp. 57-82.

CALDENTEY, P. Y GÓMEZ, A. C. (1997): «Productos Agroalimentarios Típicos y Territorio», Distribución y Consumo, Vol. 31, pp. 69-74.

CAMBRA, J. Y VILLAFUERTE, A. (2009): «Denominaciones de origen e indicaciones geográficas: justificación de su empleo y valoración de su situación actual en España», en LAMO DE ESPINOSA, J. (ed.) El nuevo sistema agroalimentario en una crisis global, Serie Mediterráneo Económico, Fundación Cajamar, Almería, pp. 329-350

CHAMBOLLE, C. Y GIRAUD-HÉRAUD, E. (2005): «Certification of origin as a non-tariff barrier», Review of International Economics, Vol. 13, No. 3, pp. 461-471.

CHAMORRO, A., MIRANDA, F. J., RUBIO, S. Y VALERO, V. (2008): «Análisis del proceso de compra del jamón ibérico en España», Distribución y Consumo, Vol. 101, pp. 50-58.

CHAO, P. (1998): «Impact of country-of-origin dimensions on product quality and design quality perceptions», Journal of Business Research, Vol. 42, pp. 1-6

CHATFIELD, C. (1989): The analysis of time series: an introduction, $4^{\text {th }}$ ed., Chapman \& Hall.

EDEN, S., BEAR, C. Y WALKER, G. (2008): «Understanding and (dis)trusting food assrance schemes: consumer confidence and the 'knowledge fix'», Journal of Rural Studies, Vol. 24, pp. 1-14.

EL ECONOMISTA (2009): «¿Navidad sin jamón serrano? El sector prevé una caída de las ventas del 20\%», 11 de diciembre (disponible en http://www.eleconomista.es/empresas-finanzas/noticias/1764285/12/09/Se-avecina-una-Navidad-sin-jamon-serrano-El-sector-preve-una-caida-delas-ventas-del-20.html).

EXPANSIÓN (2009a): «Sobra un millón de jamones ibéricos y los precios caen», 28 de noviembre (disponible en http://www.expansion.com/2009/11/27/empresas/1259362721.html).

EXPANSIÓN (2009b): «La crisis se ceba con el sector alimentario», 17 de marzo (disponible en http://www.expansion.com/2009/03/17/entorno/1237323130.html).

GÓMEZ, A. C. Y CALDENTEY, P. (1999): «Signos Distintivos en Productos Agroalimentarios», Distribución y Consumo, Vol. 45, pp. 71-81. 
HAN, C. Y TERPSTRA, V. (1988): «Country-of-origin effects for uni-national and bi-national products», Journal of International Business Studies, Vol. 20, No. Summer, pp. 235-254

HARVEY, A. (1993). Time series models, $2^{\text {nd }}$ ed., Hemel Hempstead: Harvester Wheatsheaf.

HÄUBL, G. Y ELROD, T. (1999): «The impact of congruity between brand name and country of production on consumers' product quality judgements», International Journal of Research in Marketing, Vol. 16, pp. 199-215.

HUSTVEDT, G. Y BERNARD, J. (2008): «Consumer willingness to pay for sustainable apparel: the influence of labelling for fibre origin and production methods», International Journal of Consumer Studies, Vol. 32, pp. 491-498.

INSCH, G. Y MCBRIDE, J. (2004): «The impact of country-of-origin cues on consumer perceptions of product quality. A binational test of the decomposed country-of-origin construct», Journal of Business Research, Vol. 57, pp. 256-265.

JAVALGI, R., CUTLER, B. Y WINANS, W. (2001): «At your service; Does country of origin research apply to services?», Journal of Services Marketing, Vol. 15, No. 7, pp. 565-583.

JIMÉNEZ, A. I. (2002): «La percepción de las denominaciones de origen mancha y Valdepeñas de España», Agroalimentaria, Vol. 7, No. 14, pp. 51-68.

JIMÉNEZ, A. I. Y GÓMEZ, M.A. (1997): «La denominación de origen como marca. La procedencia del producto como elemento de identidad», Investigación y Marketing, Vol. 55, pp. 57-66.

JIMÉNEZ, J.F., GÁZQUEZ, J.C. Y SÁNCHEZ, R. (2006): «La capacidad predictiva en los métodos Box-Jenkins y Holt-Winters: una aplicación al sector turístico», Revista Europea de Dirección y Economía de la Empresa, Vol. 15, No. 3, pp. 185-198.

KAO, J., Y HUANG, S. (2000): «Forecast using neural network versus Box-Jenkins methodology for ambient air quality monitoring data», Journal of Air \& Waste Management Association, Vol. 50, pp. 219-226.

KRYSTALLIS, A. Y NESS, M. (2005): «Consumer preferences for quality foods from a South European perspective: a conjoint analysis implementation on Greek olive oil», International Food and Agribusiness Management Review, Vol. 8, No. 2, pp. 62-91.

LIEFELD, J. (1993): «Experiments on country-of-origin effects: review and meta-analysis of effect size», en N. Papadopoulos y L.A. Haslop (eds.), Product and country. Images, Binghamton, NY: International Business Press, pp. 117-156.

MAHESWARAN, D. Y CHEN, C. (2006): «Nation equity: incidental emotions in country-of-origin effects», Journal of Consumer Research, Vol. 33, No. December, pp. 370-376.

MARONICK, T. (1995): «An empirical investigation of consumer perceptions of "Made in U.S.A." claims», International Marketing Review, , Vol. 12, No. 3, pp. 15-30.

MARTÍN, V. (2006): «Denominaciones de origen: una revisión en el mercado alimentario español», Distribución y Consumo, Vol. 90, pp. 87-113.

MARTÍN, V. (2009): «Denominaciones de origen y calidad diferenciada en el mercado alimentario español», Distribución y Consumo, Vol. 106, pp. 89-102.

MARTÍNEZ-CARRASCO, L., BRUGAROLAS, M. Y DEL CAMPO, F. (2001): «Importancia del conocimiento del consumidor para las bodegas acogidas a la DO Alicante», ESIC-Market, Vol. 110, pp. 209-223.

MINISTERIO DE AGRICULTURA, PESCA Y ALIMENTACIÓN (MAPA) (2005): Actitud de los consumidores ante las Denominaciones de Origen de Jamón de Cerdo Ibérico.

MINISTERIO DE AGRICULTURA, PESCA Y ALIMENTACIÓN (MAPA) (2006): Hacia dónde camina la alimentación, tendencias de consumo y de comercialización. El etiquetado de los alimentos.

MINISTERIO DE MEDIO AMBIENTE, MEDIO RURAL Y MARINO (MARM) (VARIOS AÑOS): «Datos de las denominaciones de origen protegidas e indicaciones geográficas protegidas de productos agroalimentarios», subdirección general de calidad diferenciada y agricultura ecológica (disponible en http://www.Mapa.Es/alimentacion/pags/denominacion/documentos/). 
MINISTERIO DE MEDIO AMBIENTE, MEDIO RURAL Y MARINO (MARM) (2009). «Datos de las denominaciones de Origen Protegidas e Indicaciones Geográficas Protegidas de productos agroalimentarios. Año 2008», Subdirección General de Calidad Diferenciada y Agricultura Ecológica (http://www.mapa.es/alimentacion/pags/denominacion/documentos/Agroalimentarios2008.pdf).

MOUSSA, S.Y TOUZANI, M. (2008): «The perceived credibility of quality labels: a scale validation with refinement», International Journal of Consumer Studies, Vol. 32, pp. 526-533.

OTERO, J. Y TRUJILLO, F. (1998): «Forecasting tourism demand in the short term: the case of Andalusian hotel establishments», $4^{\text {th }}$ International Forum on Tourism Statistics, Copenhague, Dinamarca.

OZRETIC-DOESEN, D., SKARE, V. Y KRUPKA, Z. (2007): «Assessments of country of origin and brand cues in evaluating a Croatian, western and eastern European food product", Journal of Business Research, Vol. 60, pp. 130-136.

OZSOMER, A. Y CAVUSGIL, S. (1991): «Country of origin effects on product evaluations: a sequel to Bilkey and Nes review», en M. C. Gilly y F. R. Dwyer (eds.) AMA Educators' Proceedings, Chicago: AMA, pp. 269-277.

PHARR, J. (2005): «Synthesizing country-of-origin research from the last decade: is the concept still salient in an era of global brands?», Journal of Marketing Theory and Practice, Vol. 13, No. 4, pp. 34-45.

POLO, Y. Y CAMBRA, J. (2006): «The long-term orientation of firm-suppliers relationships: analysis of moderating effect of belonging to an agro-food protection system», Journal of Food Products Marketing, Vol. 12, pp. 79-108.

SANZ, J. Y MACÍAS, A. (2005): «Quality certification, institutions and innovation in local agrofood systems: Protected designations of origin of olive oil in Spain», Journal of Rural Studies, Vol. 21, pp. 475-486.

SCHUlZE, H., ALBERSMEIER, F., GAWRON, J-C., SPILLER,A. Y THEUVSEN, L. (2008): «Heterogeneity in the evaluation of quality assurance systems: the international food standard (IFS) in European agribusiness», International Food and Agribusiness Management Review, Vol. 11, No. 3, pp. 99-139.

SRINIVASAN, N. Y JAIN, S. (2003): «Country of origin effect: synthesis and future», en S. Jain (ed.) Handbook of research in international marketing, Cheltenham, UK: Edward Elgar, pp. 458-476.

URIEL, E. Y MUÑIZ, M. (1993): Estadística económica y empresarial. Teoría y ejercicios. AC: Madrid.

VAN ITTERSUM, K., CANDEL, M. Y MEULENBERG, M. (2003): «The influence of the image of a product's region of origin on product evaluation», Journal of Business Research, 56, pp. 215-226.

VERLEGH, P. Y STEENKAMP, JB. (1999): «A review and meta-analysis of country of origin research», Journal of Economic Psychology, Vol. 20, No. 5, pp. 521-546.

VERLEGH, P., STEENKAMP. JB. Y MEULENBERG, T. (2005): «Country-of-origin effects in consumer processing of advertising claims», International Journal of Research in Marketing, Vol. 22, pp. 127-139.

ZOU, H. Y YANG, Y. (2004): «Combining time series models for forecasting», International Journal of Forecasting, Vol. 20, No. 1, pp. 69-84.

WILSON, P., OKUNEV, J., ELLIS, C., HIGGINS, D. (2000): «Comparing univariate forecasting techniques in property markets», Journal of Real Estate Portfolio Management, Vol. 6, No. 3, pp. 283-306.

YAGÜE, M. J. (1996): «Otras formas de competir: diferenciación de productos y comercialización», Situación: Serie de Estudios Regionales, Vol. 1, pp. 201-215. 
